\title{
The Mediterranean outflow in the Strait of Gibraltar and its connection with upstream conditions in the Alborán Sea
}

\author{
Jesús García-Lafuente, Cristina Naranjo, Simone Sammartino, José C. Sánchez-Garrido, and Javier Delgado \\ Physical Oceanography Group, Department of Applied Physics 2, University of Málaga, Málaga, Spain \\ Correspondence to: Jesús García-Lafuente (glafuente@ctima.uma.es)
}

Received: 23 November 2016 - Discussion started: 13 December 2016

Revised: 24 February 2017 - Accepted: 28 February 2017 - Published: 24 March 2017

\begin{abstract}
The present study addresses the hypothesis that the Western Alborán Gyre in the Alborán Sea (the westernmost Mediterranean basin adjacent to the Strait of Gibraltar) influences the composition of the outflow through the Strait of Gibraltar. The process invoked is that strong and welldeveloped gyres help to evacuate the Western Mediterranean Deep Water from the Alborán basin, thus increasing its presence in the outflow, whereas weak gyres facilitate the outflow of Levantine and other intermediate waters. To this aim, in situ observations collected at the Camarinal (the main) and Espartel (the westernmost) sills of the strait have been analysed along with altimetry data, which were employed to obtain a proxy of the strength of the gyre. An encouraging correlation of the expected sign was observed between the time series of potential temperature at the Espartel Sill, which is shown to keep information on the outflow composition, and the proxy of the Western Alborán Gyre, suggesting the correctness of the hypothesis, although the weakness of the involved signals does not allow for drawing definitive conclusions.
\end{abstract}

\section{Introduction}

The Mediterranean outflow through the Strait of Gibraltar can be considered to be formed by up to four water masses of different origins (see Naranjo et al., 2015, for a recent analysis of the outflow composition). Of all the four, the Levantine Intermediate Water, characterized by an absolute maximum of salinity, and the Western Mediterranean Deep Water, which is the densest and often the coldest water, have been historically seen as the main contributors to the outflow. The two remaining water masses are the Winter Inter- mediate and the Tyrrhenian Dense waters, both of intermediate nature. The Winter Intermediate Water is formed along the continental shelf of the Liguro-Provençal sub-basin and Catalan Sea (Conan and Millot, 1995; Vargas-Yáñez et al., 2012), exhibits marked interannual fluctuations that include years of no formation (Pinot et al., 2002; Monserrat et al., 2008), and is characterized by an absolute minimum of potential temperature. Its volume transport is much less than the Levantine Intermediate Water and it flows embedded inside this water mass at relatively shallow depths. The Tyrrhenian Dense Water is the result of mixing of old Western Mediterranean Deep Water residing in the Tyrrhenian Sea and newly entered Levantine Intermediate Water flowing into the western Mediterranean Sea through the Strait of Sicily (Rhein et al., 1999; Millot et al., 2006). It is slightly denser than the Levantine Intermediate Water but lighter than the Western Mediterranean Deep Water and spreads between both of them.

In the Alborán Sea, which is the upstream basin for the outflow, these waters approach the strait following different paths, with the Levantine and Western Intermediate waters flowing closer to the Spanish continental slope and the Western Mediterranean Water attached to the Moroccan coast (Bryden and Stommel, 1982; Parrilla et al., 1986; Millot, 2009; Naranjo et al., 2012). This spatial differentiation is still observed before they flow over the Camarinal Sill (see Fig. 1) in the eastern half of the strait (García-Lafuente et al., 2000; Naranjo et al., 2012, 2015). The severe mixing and dissipation that takes place in the Tangier Basin downstream (oceanward) of the Camarinal Sill (Wesson and Gregg, 1994; García-Lafuente et al., 2009, 2011; Sánchez-Garrido et al., 2011) blurs this spatial pattern and tends to form a rather mixed outflow with little participation of entrained North At- 
lantic Central Water in which the Mediterranean waters are barely distinguishable (García-Lafuente et al., 2011; Naranjo et al., 2015).

The bottom topography of the Camarinal Sill section depicts two troughs (Fig. 1). According to the spatial differentiation in the Alborán Sea and east of the Camarinal Sill, the Levantine and Western Intermediate waters (and Tyrrhenian Dense Water partially) will flow preferably through the northern channel of the Camarinal Sill (CSN hereinafter; see Fig. 1), and the Western Mediterranean Deep Water (and Tyrrhenian Dense Water partially as well) will go across the southern channel (CSS hereinafter). On the other hand, bearing in mind the different paths they follow in the Alborán Sea, the Western Mediterranean Deep Water flow would benefit from a well-developed Western Alborán Gyre (WAG), a recurrent mesoscale feature of this sub-basin (Parrilla et al., 1986; Viudez et al., 1998), whereas the Levantine and also the Western Intermediate waters would be favoured by a weak or absent WAG. While the first process has been dealt with by different authors (Bryden and Stommel, 1982; Naranjo et al., 2012), the influence of the WAG on the Levantine/Western Intermediate waters flow seems to not have been addressed yet.

The hypothesis of the present study is that if the WAG has an effect on the evacuation of these water masses, one expected consequence at the Camarinal Sill section would be the variation of the outflow size across each channel, the presence of a well-developed WAG increasing the size of the flow across CSS with regard to CSN, and vice versa. Two mooring lines equipped with autonomous conductivitytemperature (CT) and upward-looking acoustic Doppler current profilers (ADCPs) were deployed in these channels (Fig. 1) in order to get information about the characteristics and properties of the outflow at the Camarinal Sill section. Since the flow through each channel advects water of different characteristics that mix downstream of the Camarinal Sill, changing fractions of these flows can leave a footprint in the hydrological characteristics of the resulting mixed water that courses towards the Atlantic Ocean and contribute to the low-frequency signals reported in the Mediterranean outflow in the Gulf of Cádiz (Fusco et al., 2008; Bellanco et al., 2016). This outflow is being monitored by a long-term monitoring station deployed few tens of kilometres westwards of the Camarinal Sill at the Espartel Sill in the year 2004 (ESP hereinafter, Fig. 1; see Sammartino et al., 2015, for a complete description of this station) and the collected long time series has been analysed to investigate our hypothesis as well. These observations have been complemented with altimetry data that have been employed to define a proxy of the WAG strength for checking the hypothesized WAG influence on the outflow composition. Regarding the objective of this paper, each set of the available in situ observations has its own pros and cons. The instruments deployed at CSN and CSS sample Mediterranean waters that have not undergone important mixing yet, which is a clear benefit for their identification, and the time series they collect (described in more detail in next section) are well suited to investigate the spatial structure of the outflow through the Camarinal Sill. Both aspects are of great interest to our study. However, taking into account that the timescale of the WAG variability is of the order of weeks to months (Vargas-Yáñez et al., 2002; Sánchez-Garrido et al., 2013), these series are too short to draw unarguable conclusions about our hypothesis. This drawback does not apply to the long series at ESP, which shows up other disadvantages: since the characteristics of the Mediterranean waters flowing through CSN and CSS are not very different and the changing fractions that the WAG fluctuations can originate on these flows are also small, the footprint left by these fluctuations in the series collected at ESP are expectedly weak. This remark is of concern because other processes taking place in the Mediterranean Sea produce signals that, when exported through the strait, can mask the weaker ones associated with the WAG fluctuations. One of them is, for instance, the formation of larger-than-average volumes of denser-than-average Western Mediterranean Deep Water in winter, as it happened in the years 2005 and 2006, which can uplift old deep water near the strait and facilitate its drainage rather independently of the WAG features, causing a cold signature in the temperature series at ESP (García-Lafuente et al., 2007). The interannual variability of the Mediterranean water properties may also interfere with the mechanism we propose. Last but not least, the entrained North Atlantic Central Water that has been incorporated to the outflow at this site, despite being a very small fraction (García-Lafuente et al., 2011), also contributes to blurring possible signals (see Appendix A).

Despite the aforementioned sources of "unwanted noise" and observational limitations, our analysis provides reasonable evidence to support the feasibility of the hypothesis, even if it cannot be validated indisputably. The main goal of this paper is, therefore, to present and discuss this evidence bearing in mind these limitations, and has been organized as follows: the next section describes the experimental data and the data processing and presents some features visible from the processed data. Of particular interest is the corroboration of the aforementioned north-south spatial distribution of Levantine Intermediate/Western Mediterranean Deep waters through CSN/CSS channels. Section 3, which is divided into two subsections, presents the results of the data analysis. The first subsection analyses the 3-month field experiment carried out in the Camarinal Sill, while the second one makes use of the multi-year time series collected at the Espartel Sill to test our hypothesis. Finally, Sect. 4 discusses our findings and summarizes our conclusions. 


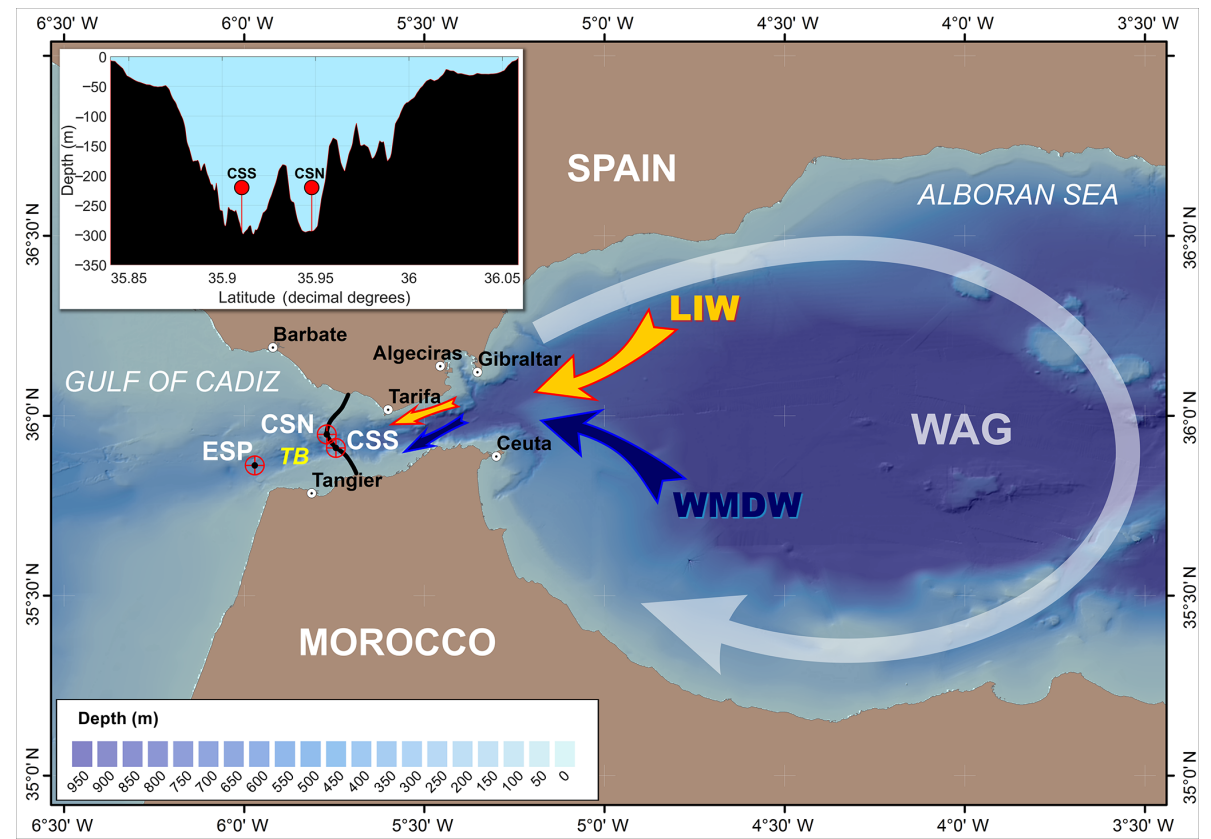

Figure 1. Map of the Strait of Gibraltar and westernmost area of the Alborán Sea. The inset on the upper left corner shows the bathymetry of the Camarinal Sill section (solid black line in the map) and the location of the two mooring lines deployed in the north and south channels of the section (sites CSN and CSS, respectively). The locations of the Espartel Sill long-term monitoring station of the outflow (ESP) and the Tangier Basin (TB) between both sills are also indicated. Coloured arrows sketch the main path of Levantine Intermediate and Western Mediterranean Deep waters (LIW and WMDW, respectively) in the Alborán Sea and in the eastern half of the strait. The Western Alboran Gyre is represented by the white arrow.

\section{Data and data processing}

\subsection{Observations}

\subsubsection{In situ observations}

Two twin mooring lines equipped with a CT probe and an upward-looking ADCP located at 10 and $12 \mathrm{~m}$ above the seafloor, respectively, were deployed in CSN and CSS channels at the Camarinal Sill section (Fig. 1) at bottom depths of 306 and $310 \mathrm{~m}$, respectively, during oceanographic surveys carried on the Angeles Alvariño research vessel from the Instituto Español de Oceanografía. The ADCP observations span the period between 9 June and 25 September 2013, with a sampling interval of $4 \mathrm{~min}$. The instruments were configured to sample 40 vertical bins, each $6 \mathrm{~m}$ thick, so that the velocity profile does not reach the sea surface although it covers the depth range of the outflow. The CT observations at CSN and CSS were made every 2 min and also started on 9 June, but finished earlier due to battery depletions (on 24 and 27 August at CSN and CSS, respectively).

The historical time series of the outflow properties collected by the monitoring station deployed at ESP at $360 \mathrm{~m}$ depth started in the year 2004 and continues to the present. The instrument configuration of the monitoring station is similar to that of the lines deployed at the Camarinal Sill although it contains additional probes to measure $\mathrm{pH}$ and $\mathrm{CO}_{2}$
(Flecha et al., 2015), which are not used here. More information about the station can be found in Naranjo et al. (2015), or Sammartino et al. (2015). As seen below, only the potential temperature measured at around $15 \mathrm{~m}$ above the seafloor from October 2004 to October 2015, sampled every $30 \mathrm{~min}$, has been used in the present study (García-Lafuente et al., 2016).

The conductivity and temperature sensor of all the CT probes has an accuracy of $\pm 3 \times 10-3 \mathrm{mS} \mathrm{cm}^{-1}$ at $12^{\circ} \mathrm{C}$ and $\pm 2 \times 10^{-4}{ }^{\circ} \mathrm{C}$, respectively, while the precision is $1 \times 10^{-4} \mathrm{mS} \mathrm{cm}^{-1}$ for the conductivity and $1 \times 10^{-4}{ }^{\circ} \mathrm{C}$ for the temperature. The horizontal velocity measured by the ADCPs of the twin moorings of the CS has a resolution of $1 \mathrm{~mm} \mathrm{~s}^{-1}$ while its accuracy is $1 \mathrm{~cm} \mathrm{~s}^{-1}$.

\subsubsection{Altimetry data}

Sea level anomaly data have been downloaded from CMEMS ("Mediterranean sea L4 gridded maps rep SLA" from Copernicus Marine Environment Monitoring Service, http: //marine.copernicus.eu), formerly distributed by AVISO. The product used here is a reanalysis of multi-altimeter satellite where sea surface heights were computed with respect to a 20 -year mean and optimally interpolated to finally supply a gridded product with horizontal resolution of $1 / 8^{\circ}$ in the Mediterranean Sea and with daily temporal resolution. 


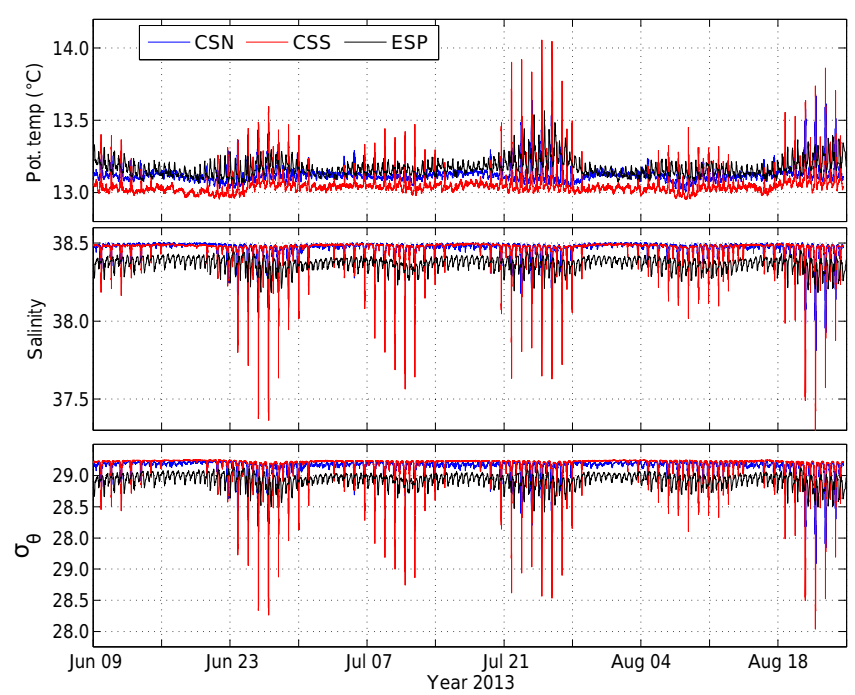

Figure 2. Time series of potential temperature, salinity, and $\sigma \theta$ collected at CSN, CSS, and ESP sills (see legend). The strong fluctuations correspond to periods of spring tide and are greater in CSS than in CSN, being the smallest in ESP. A noteworthy fact is the similitude of CSN and ESP temperature (CSS is clearly cooler) and of CSN and CSS salinity (ESP is clearly fresher).

\subsection{The processed time series}

\subsubsection{Temperature and salinity}

Figure 2 illustrates the typical strong tidal-induced variability of local temperature and salinity registered at the depths of the CT probes in CSN, CSS and ESP. Such variability masks the characteristics that the different outflowing water masses would have if tides were absent. A procedure to obtain a realistic estimation of such characteristics is to select the coldest or saltiest sample registered during each semi-diurnal tidal cycle, as in García-Lafuente et al. (2009). With regard to the Camarinal Sill section and under the hypothesis that Levantine Intermediate Water flows preferably through CSN, the saltiest option would be the right choice to select the representative long term there, whereas the coldest option is more adequate to select samples in CSS, since Western Mediterranean Deep Water has a preference to flow attached to the Moroccan coast. For comparison purposes, however, the criterion must be the same, in which case the best option is to pick up the densest sample.

These samples are systematically observed near high water (Fig. 3), a fact that supports the procedure for selecting the most representative Mediterranean water samples: the barotropic tide in the strait behaves like a standing wave (García-Lafuente et al., 1990; Candela et al., 1990) with the current heading west during the rising tide (flood) and east during the falling tide (ebb). Therefore, it is at the end of the flood that the water parcels located farther east on the Mediterranean side of the strait can reach and overflow the

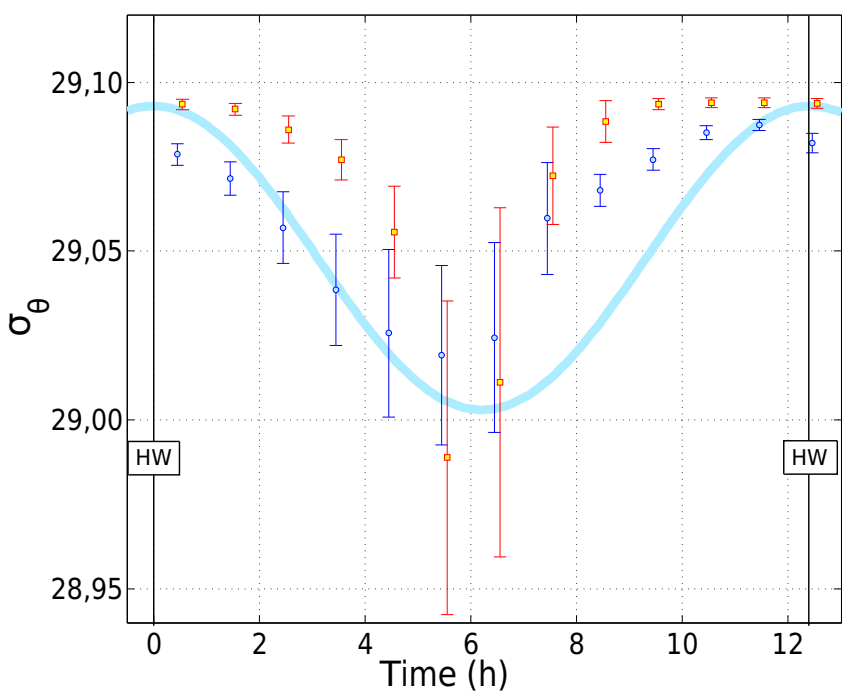

Figure 3. Mean $\sigma_{\theta}$ values at CSN (blue circles) and at CSS (red squares) and standard deviation (bars) of all observations grouped in $1 \mathrm{~h}$ length bins. The curve refers to the sea level oscillation at Tarifa (see Fig. 1 for location) and HW stands for high water. The first bin includes all samples collected between HW and HW $+1 \mathrm{~h}$ regardless the date, the second one the samples between $\mathrm{HW}+1$ and $\mathrm{HW}+2$, and so on. The highest $\sigma \theta$ values (which also have minimum SD) are regularly observed near HW, whereas the lowest values spread around low water and show a marked variability.

sill. Moreover, they will be the least-modified parcels by tidal mixing, which otherwise becomes more apparent over the sill near low water when the ebb current may reverse the "mean" flow and bring back to the Mediterranean Sea the water intensely mixed westwards (downstream) of the Camarinal Sill (Wesson and Gregg, 1994; Sánchez-Garrido et al., 2013).

The result of this selection is displayed in Fig. 4. Figure 4a shows the $T-S$ diagram of the whole set of recorded data. Several historical conductivity-temperaturedepth (CTD) casts collected at ESP are also displayed to illustrate the mixing between Mediterranean water and North Atlantic Central Water. The inset enlarges the area inside the black rectangle to show the subsets of data selected by the maximum-density procedure. Despite some overlapping of CSN and CSS data subsets, they are visually and statistically differentiable, confirming the hypothesis that Levantine Intermediate Water (and eventually other intermediate waters) flows out more attached to the northern half of the Camarinal Sill in the bottom layer and the Western Mediterranean Deep Water to the southern half. CTD data from ESP display the result of the mixing of waters flowing out through CSN and CSS with each other and with the overlying North Atlantic Central Water, and how the differentiation observed at the Camarinal Sill has already vanished. 


\subsubsection{Outflow per unit width}

The ADCP observations have been integrated from the seafloor to the depth of the interface in order to obtain an estimate of the outflow per unit width across CSN and CSS channels. The velocity in the bottom layer has been extrapolated by fitting a logarithmic law on the deeper ADCP bins from the depth of the deepest velocity to the seafloor where the velocity is set to zero. The most sensitive issue is the choice of the interface depth, which stems from the regular reversals of the tidal currents in the Camarinal Sill (Candela et al., 1990; Bryden et al., 1994; García-Lafuente et al., 2000). Under these circumstances, the best option can possibly be the selection of a material surface, usually an isohaline close to 37.3-37.5 (Bryden et al., 1994; García-Lafuente et al., 2000; Naranjo et al., 2014). However, this choice cannot be applied because of the lack of salinity profiles. An alternative solution, adopted here, is to take the depth of maximum velocity shear as the interface, as in Sánchez-Román et al. (2009) or Sammartino et al. (2015). In order to deal with the possible spikes in the ADCP velocity record, prior to computing flows, the current profiles have been smoothed vertically with a cubic polynomial fit with $1 \mathrm{~m}$ resolution and temporally with a 20 min moving average.

The computed flows per unit width are dominated by tides (Fig. 5a), with values ranging from -433 to $+348 \mathrm{~m}^{2} \mathrm{~s}^{-1}$ (mean value $-118 \mathrm{~m}^{2} \mathrm{~s}^{-1}$ ) in CSN and -499 to $+253 \mathrm{~m}^{2} \mathrm{~s}^{-1}$ (mean value of $-132 \mathrm{~m}^{2} \mathrm{~s}^{-1}$ ) in CSS, the minus sign indicating flow towards the Atlantic Ocean. In a first step, this high-frequency tidal variability has been removed with a low-pass filter of $3^{-1} \mathrm{cpd}$ (cycles per day) cutoff frequency and the ensuing series are plotted in Fig. 5b.

\subsubsection{Western Alborán Gyre}

Altimetry data were processed to extract a proxy of the WAG strength. Because the WAG forms part of a complex surface circulation system in the Alborán Sea, several proxies dealing with the different oceanographic features of this system could be tried on. However, as long as the WAG is the nearest feature to the Strait of Gibraltar, using a WAG-related proxy is the best option. To this aim, the location of maximum sea level anomaly within the Western Alborán basin has been identified as the centre of the WAG. Starting from this point, the first local minimum of sea level anomaly in the northward direction has been found, and the sea level difference between both points has been considered as the "height" of the gyre in that direction. The same procedure has been applied to the three other cardinal directions, and the averaged value of the four height anomalies has been adopted as the proxy of the WAG strength. We have also tried the mean sea surface gradient of the WAG, computed by dividing the height by the mean radius of the gyre, as an alternate proxy. The radius was estimated as the average distance from the centre of the WAG to the location of the local minimum in the four cardinal directions. The relatively coarse horizontal resolution of AVISO data produces a pronounced step-like series of the mean radius that does not change the pattern depicted by the height series too much, but nevertheless introduces noise in the gradient series. Therefore, we opted for the first proxy, namely the height of the WAG, which is plotted in Fig. 5d. Similar procedures have been followed in the literature to estimate geostrophic circulation patterns from altimetry data (Naranjo et al., 2012; Lique et al., 2015).

\section{Results}

\subsection{The observations at the Camarinal Sill and the Western Alborán Gyre}

The panels of Fig. $4 \mathrm{~b}$ show that the procedure of selecting the maximum density samples does not remove the fortnightly tidal variability in the series of temperature and salinity. The fortnightly cycle makes the flow through both channels fresher and colder during spring tide and saltier and warmer during neap tides. Since the temperature and the salinity act in opposite directions, the density series shows smoothed fortnightly fluctuations, though it still shows a tendency to be lighter in spring and denser in neap tides, particularly at CSS (results not shown). These fluctuations are explained in terms of local enhanced (reduced) mixing with the overlying North Atlantic Central Water (Candela et al., 1990; Bryden et al., 1994; García-Lafuente et al., 2000) and, to a lesser extent, with higher (lower) Western Mediterranean Deep Water aspiration driven by the enhanced (reduced) tidal currents over the sill in spring (neap) tides (Kinder and Bryden, 1990).

A similar fortnightly variability is seen in the filtered series of flow per unit width through CSN and CSS (Fig. 5b). The flows are weaker in spring tides, a fact that has been ascribed to the aforementioned increase of the mixing during this phase of the cycle which reduces the effective density contrast between the exchanged flows, that is, the driving force of the exchange through the strait (Bryden et al., 1994; García-Lafuente et al., 2000). Both subtidal flows are highly correlated ( $R=0.92$ at $95 \%$ confidence level), indicating a coherent cross-strait structure of the velocity field. Nevertheless, there are small, though noteworthy, dissimilarities, which are just the features of interest and which are better seen in the series of the difference of low-passed flows presented in Fig. 5c. It shows that the flow (in absolute value, that is, the outflow) is greater through the southern channel all the time except for a few days by the end of August and beginning of September when the flow difference is negative, indicating greater outflow through CSN (see also Fig. 5b).

This flow difference has been compared with the series of the proxy of the WAG (Fig. 5d). The latter is not expected to exhibit much variability at short timescales due to the limited time resolution of the altimetry products. Even so, Fig. 5d shows several minima, two of which are particularly notice- 

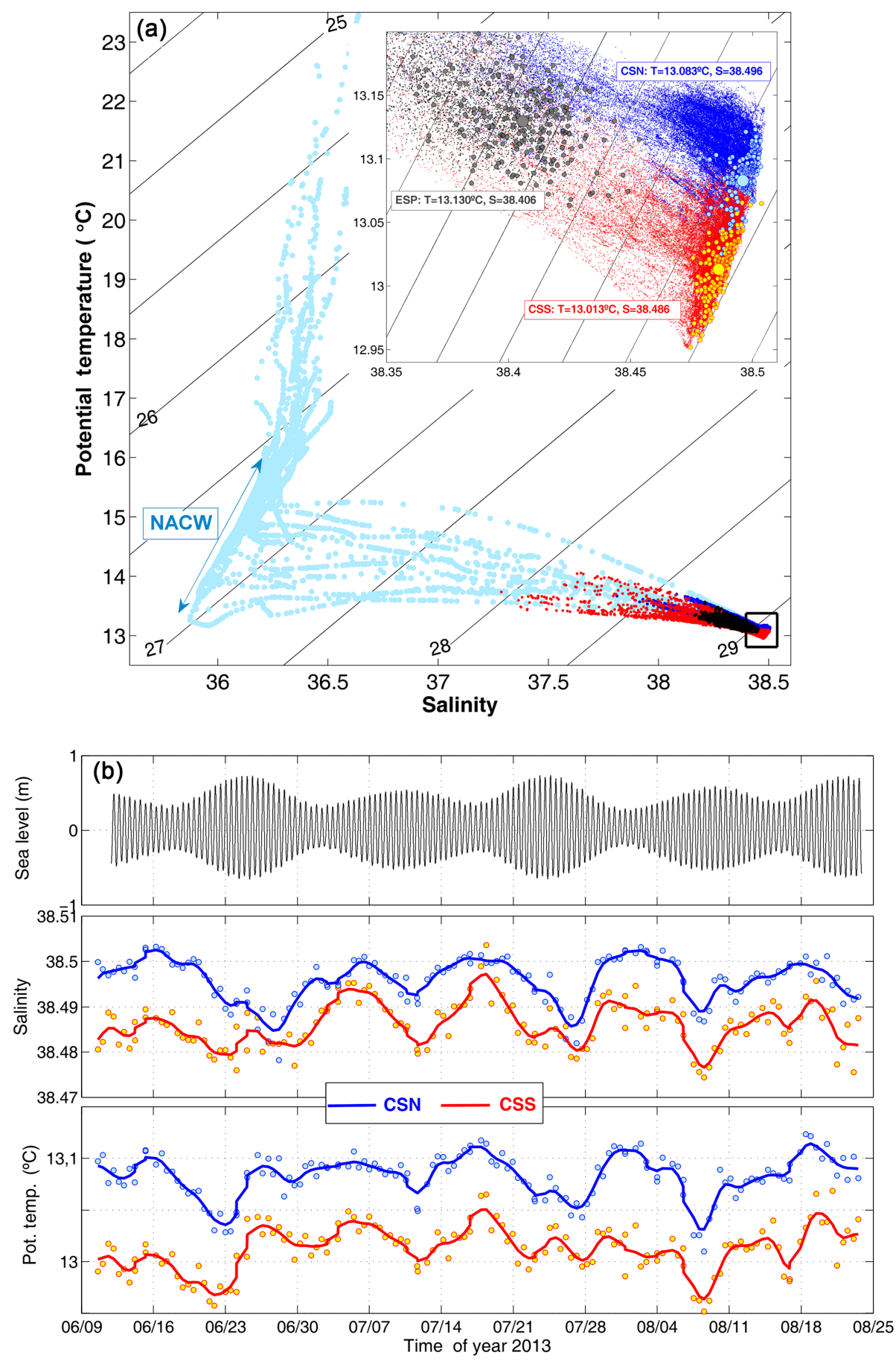

Figure 4. (a) $T-S$ diagram of all samples recorded at CSN (blue), CSS (red), and ESP (black). Historical CTD casts collected at ESP site are displayed in light-blue dots. The typical linear temperature-salinity relationship is sketched by the double-headed arrow. The inset zooms on the area inside the black rectangle to show the subset of maximum density samples at each site (filled circles with the same colour code). Large filled circles indicate the mean values, which are also specified in the text boxes. (b) Time evolution of potential temperature and salinity of the subset of maximum density (coloured dots) and a 2-day low-pass-filtered version of them (solid lines). Top panel is the sea level at Tarifa, which is included to illustrate the fortnightly cycle of the variables, more visible in the salinity series.

able due to the marked decrease of the proxy from relatively high values: the first one occurs at the beginning of August and the second one by the end of this month and beginning of September. They would point to a weakening, or even a disappearance, of the WAG, particularly during the second event when sea level anomaly AVISO maps show no signs 


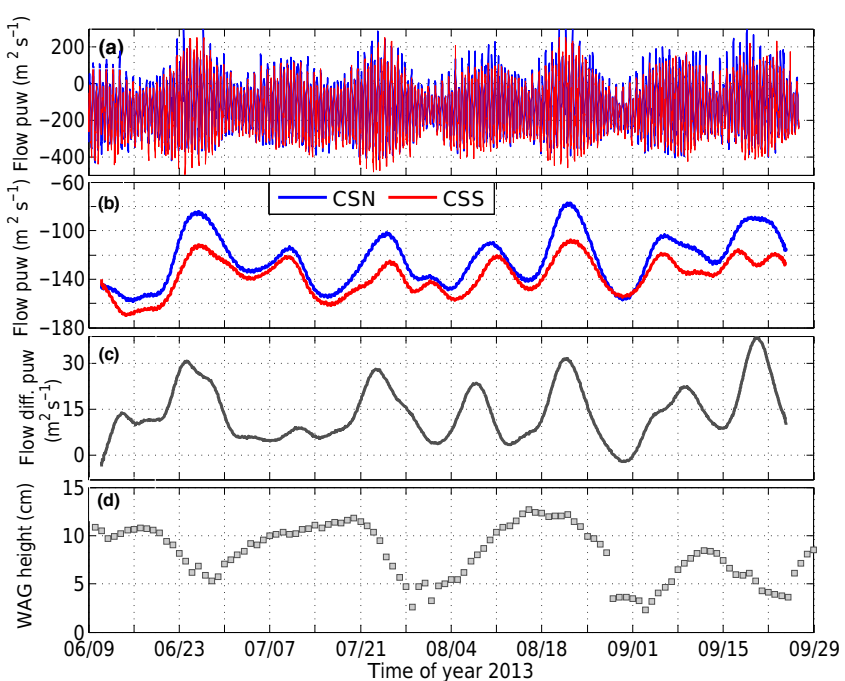

Figure 5. (a) Instantaneous flows per unit width across CSN and CSS (see legend). Negative sign indicates flow towards the Atlantic Ocean (outflow). (b) Low-passed flows per unit width. (c) Lowpassed flow difference per unit width, computed as CSN-CSS from panel (b). This difference is positive whenever the outflow through CSS is greater than through CSN, since both flows are negative. (d) Daily mean sea surface height of the WAG (see text for details).

of WAG at all. The flow difference shows minima in both cases, the second one being the situation of greater outflow through CSN mentioned above (Fig. 5c). Notice also that the two height maxima by the second half of July and August in Fig. 5d (stronger WAG) are roughly coincidental with similar local maxima of the flow difference (enhanced flow across CSS). All this agrees with the hypothesis that a weak WAG facilitates the outflow of Levantine Intermediate Water through CSN, while a strong WAG does the same with Western Mediterranean Deep Water through CSS. However, there are several notorious discrepancies (the minima flow differences by the middle of August and September, for instance) that do not allow for drawing unquestioned conclusions. A reason for this drawback could be the expected small size of the signal induced by WAG fluctuations on the flow structure across the Camarinal Sill, which moreover is contaminated by the stronger fortnightly signal (Fig. 5b, c) and other energetic processes taking place in the strait. Should the hypothesized cause-effect be a physical process, as the previous analysis partially supports, its identification with some degree of reliability would require significantly longer time series like those available at ESP.

\subsection{The observations at the Espartel Sill and the Western Alborán Gyre}

The time series of salinity and temperature in CSN and CSS may not be particularly sensitive to the WAG fluctuations, even if the flows per unit width are, because the flows would still carry the same type of water. The water properties at ESP, however, are the result of the strong mixing that takes place downstream of the Camarinal Sill in the Tangier Basin, which in a simple model would be given by

$X_{\mathrm{ESP}}=\alpha_{\mathrm{CSN}} X_{\mathrm{CSN}}+\alpha_{\mathrm{CSS}} X_{\mathrm{CSS}}+\alpha_{\mathrm{NAC}} X_{\mathrm{NAC}}$,

where $X$ denotes either salinity or temperature, $\alpha$ is the fraction of water involved in the mixture, and subscripts CSN and CSS refer to water flowing through CSN and CSS channels, which would have properties close to Levantine Intermediate and Western Mediterranean Deep waters, respectively. NAC indicates North Atlantic Central Water whose $T-S$ characteristics reside along a straight line of positive slope, sketched in the $T-S$ diagram of Fig. 4a by the double-headed arrow. The fractions $\alpha$ are normalized (they add up to 1) and change with time, the most notorious changes taking place at the tidal timescale when $\alpha_{\mathrm{NAC}}$ may reach high values. The changes of the fractions in the subsets of densest samples, on which we focus, are much more reduced. They must be proportional to the flows per unit width through CSN and CSS, thus inducing changes in $X_{\mathrm{ESP}}$ even if $X_{\mathrm{CSN}}$ or $X_{\mathrm{CSS}}$ do not change. Therefore, the observations at ESP are potentially useful to investigate the out-of-phase fluctuations of the flows across CSN and CSS illustrated in Fig. 5c, which allows extending our field information back to the year 2004 when the monitoring station in ESP was first deployed.

The temperature difference between the Mediterranean waters and the North Atlantic Central Water they mix with is much less than the salinity difference (Fig. 4a), which results in salinity changes greater than temperature changes at ESP with regard to the Mediterranean values. Actually, about $88 \%$ of the density difference between the mean value of the densest samples at ESP and CSN (large filled grey and blue dots in the inset of Fig. 4a, respectively) is accounted for by the salinity difference and only $12 \%$ by the temperature difference ( 72 and $28 \%$ in the case of ESP and CSS). A consequence is that the weak signals that the fluctuating flows across CSN and CSS can cause in the variables observed at ESP via Eq. (1) are expected to be better preserved in the temperature series, a fact already noted in previous works (García-Lafuente et al., 2007; Naranjo et al., 2012). In fact, Appendix A shows that any salinity signal in the Mediterranean waters identifiable at the Camarinal Sill is very probably erased at ESP if $\alpha_{\mathrm{NAC}}$ in the mixing exceeds $1 \%$, whereas temperature signals require a greater fraction of around $6-8 \%$ to be faded out. The analysis carried out in García-Lafuente et al. (2011) suggests that the fraction of North Atlantic Central Water entrained by the deep Mediterranean outflow when it passes over ESP is $4 \%$, implying that Mediterranean signals will be found more easily in temperature rather than in salinity series. Therefore, the potential temperature series is used in the following analysis.

Figure 6a shows the potential temperature series of the maximum density samples at ESP filtered with a Gaussian filter of $21^{-1}$ cpd cut-off frequency to remove the fortnightly 
variability and enhance the weaker subinertial signals. It is divided in two subseries, plotted in different colours, because the station did not register during part of the years 2011 and 2012. Figure $6 \mathrm{~b}$ shows the proxy of the WAG strength processed in the same way as the temperature series. The visual comparison of both panels suggests that maxima in potential temperature tend to happen when the height of the WAG shows minima, which is the expected behaviour in our hypothesis: a minimum WAG index corresponds to weak anticyclonic gyres, which in turn facilitate the evacuation of Levantine and other intermediate waters (more flow across CSN) and the ensuing increase of temperature in the mixed water at ESP. The opposite is expected to happen in the case of maximum WAG index, which would correspond with minima of potential temperature at ESP.

Figure $6 \mathrm{c}$ shows the lagged correlation $(R)$ of both variables using the colour code of Fig. 6a and b (see caption). The negative values confirm the anti-correlation pointed out but they also show that the maximum negative correlation does not happen at a lag of 0 . In the case of the first piece (blue curves), the minimum $R=-0.41$, which is significant at $95 \%$ confidence level, occurs at a lag of +6 days, the temperature lagging the WAG index. Such delay is consistent with a cause-effect relationship if the WAG fluctuations cause the temperature changes at ESP. García-Lafuente et al. (2009), applying an empirical orthogonal function analysis to altimetry data, found a similar delayed response in their study of the drainage of Western Mediterranean Deep Water from the Alborán Sea. The correlation diminishes to $R=-0.38$ for the second and shorter piece (red curves), and peaks at a lag of +29 days, which is an exaggerated delay that does not make much physical sense. Considering both pieces together, the correlation drops a bit more $(R=-0.35)$ and the lag decreases to an intermediate value of +18 days (grey curves). Nevertheless, it still appears as an unrealistic lag that stems from the big delay found in the second piece.

\section{Discussion and conclusions}

The hypothesis that the composition of the Mediterranean outflow through the Strait of Gibraltar may be controlled by the fluctuations of the mesoscale anticyclonic gyre in the Western Alborán Sea has been tested using in situ observations and altimetry data for two different scenarios.

The first one encompasses an extensive spatial sampling of the flow through the main sills of the strait, whose main weakness is the short duration of the collected time series. The comparison of the strength of the WAG, defined by a proxy consisting of the mean difference in sea level anomaly between its centre and its rim, with the flows through the north and south channels of the Camarinal Sill, suggests that the hypothesis is partially fulfilled since the weakening of the WAG coincides with an increase of the flow through CSN with regard to CSS (Fig. 5). However, the relationship is not

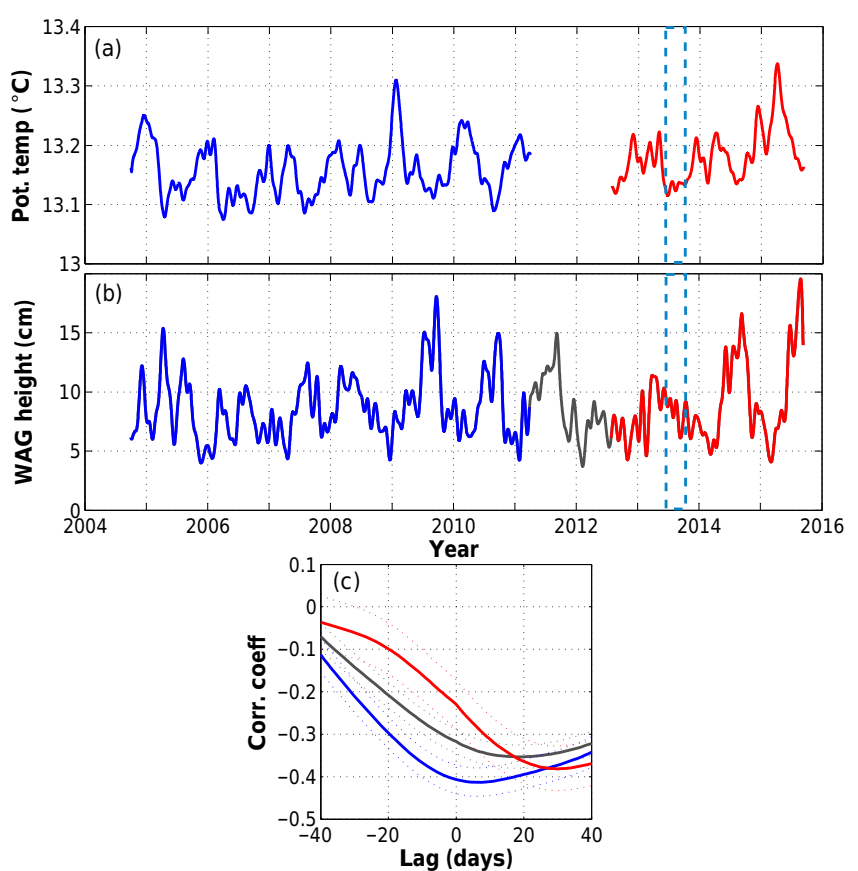

Figure 6. (a) Low-passed series $\left(21^{-1}\right.$ cpd cut-off frequency) of the potential temperature corresponding to the maximum density samples observed each semi-diurnal tidal cycle at ESP. The series has been coloured in blue and red before and after the gap of years 2011-2012, respectively. (b) Low-passed series (same filter as in a) of the WAG height, the proxy used to characterize its strength. The same colour code has been applied to the periods of the subseries in (a), whereas the period of the gap is shown in grey. (c) Lagged correlation $(R)$ between the first (blue), second (red), and whole (black) series of WAG height and potential temperature at ESP. Dashed lines indicate the $95 \%$ confidence interval for $R$; positive lags mean that the first series (height of the WAG) leads the second one (potential temperature). The 3-month period when the sampling at CS took place is indicated by the blue dashed rectangles.

accomplished nor it is poor in other situations (Fig. 5), which precludes drawing definitive conclusions. The reason we put forth this ambiguity is the short length of the series (around 3 months) that hardly covers six fortnightly cycles. The locally generated variability associated with these cycles overcomes the expected weaker signals that could come from the Mediterranean modulated by the WAG fluctuations. Filtering to remove the fortnightly cycle from such a short series would leave too few degrees of freedom to get a conclusion reasonably supported. Therefore, despite its partial support of the hypothesis, this first short-length scenario does not resolve the issue.

The second scenario involves the almost 10-year long time series collected at the Espartel Sill by a monitoring station of the Mediterranean outflow. We argued that only the potential temperature series (Fig. 6a) gathers suitable conditions to search for signals of Mediterranean origin. The series available is divided in two pieces due to technical problems dur- 
ing the years 2011-2012 (Sammartino et al., 2015). The first and longer piece provides an encouraging correlation of the correct sign $(R=-0.41)$ between potential temperature at ESP and the WAG proxy with a 6-day lag, compatible with a cause-effect relationship under our hypothesis. With regard to this piece, Fig. $6 \mathrm{~b}$ suggests an annual pattern for the WAG, the winter being the season of weaker gyres (local minima around the beginning of each of the years) and the summer and early autumn the time of better developed and robust WAGs. This seasonal pattern has been reported previously in the literature (Vargas-Yáñez et al., 2002; Naranjo et al., 2012). Therefore, according to our hypothesis, winter would be the time when Levantine Intermediate Water is more abundantly evacuated, leaving a warmer signature in the potential temperature at ESP, while summer and early autumn would favour the drainage of Western Mediterranean Deep Water, which would cause a descent of the potential temperature. In general terms, this is what Fig. 6a shows. Interestingly, some studies dealing with the properties of the Mediterranean outflow in the Gulf of Cádiz (Fig. 1) indicate saltier water in late winter-spring (Fusco et al., 2008; Bellanco et al., 2016). According to our analysis, this signal can be related to the increased proportion of Levantine Intermediate Water in the outflow during this time of the year. Caution is required, however, since other concomitant processes may be at play, such as the seasonal variability of the properties of the overlying North Atlantic Central Water driven by the wind-induced seasonal upwelling cycle along the Iberian Peninsula, as discussed in García-Lafuente et al. (2015).

The second piece, however, shows a lower correlation $(R=-0.38)$ that peaks at an unrealistic lag of 29 days. A closer inspection of this piece reveals that the expected mirror-like behaviour between both variables depicted above is satisfactorily achieved from the end of winter of the year 2014 onwards, but that it is feebly met before that time. As seen in Fig. 6b, the seasonal tendency of the WAG to form stronger gyres during late summer and early autumn is not accomplished during the years 2012 and 2013, a fact that could be due to the poorer correlation of both variables by the beginning of this second piece if we bear in mind that this seasonality appears to be the main driver of the correlation.

As mentioned in the introduction, there are other possible causes or processes not necessarily correlated with the WAG fluctuations that can leave a signature in $T_{\mathrm{ESP}}$. One of them is the winter formation of very large volumes of denserthan-average Western Mediterranean Deep Water, which uplift old deep water in the vicinity of the strait and facilitate its drainage. The two most prominent minima occurring in the years 2005 and 2006 in Fig. 6a have this origin, according to García-Lafuente et al. (2007), and they did not need the assistance of the WAG to be achieved. Even more, they occurred in late winter/early spring and not in summer, which is the season of the expected minimum $T_{\mathrm{ESP}}$ according to our hypothesis. Another cause can be the interannual variabil- ity of the Mediterranean waters themselves, with Levantine and Western Intermediate waters on one hand and Western Mediterranean Deep Water on the other. CTD casts collected in the strait in the year 2013 showed a Levantine Intermediate Water colder than usual (Naranjo et al., 2015). This fact, along with the aforementioned absence of the expectedly strong summer WAG this year, results in an unusual pattern and a reduced correlation between WAG and $T_{\mathrm{ESP}}$ during the time of the field experiment (see dashed blue rectangles in Fig. 6a, b), which is an unfortunate coincidence. Notwithstanding, during this period the WAG index displays a tendency to diminish that corresponds with a slight increase of $T_{\mathrm{ESP}}$, in agreement with out-of-phase behaviour of both variables expected under our hypothesis. Finally, another source of deviation may be the annual (seasonal) and interannual variability of the properties of the North Atlantic Central Water the Mediterranean waters mixes with (García-Lafuente et al., 2015), a mixing that, despite being driven by tides in the recurrent hydraulic transitions occurring inside the Strait of Gibraltar (Sánchez-Garrido et al., 2011), manifests itself in the long term as well. Should it be warmer than usual, the temperature signals coming from the Mediterranean Sea may not be identifiable. Such a situation could be met, for instance, if a fraction $\alpha_{\mathrm{NAC}} \geq 0.05$ of North Atlantic Central Water at $15^{\circ} \mathrm{C}$ mixes with Mediterranean waters previously mixed at a ratio $r \geq 1$ (see Fig. A2 in Appendix A). The resulting mixed water would probably lie in the zone labelled "No Mediterranean signal in $T_{\text {ESP" }}$ in Fig. A2 of Appendix A, and the correlation with the WAG fluctuations would be lost.

Despite these limitations, the reasonably good correlation found between the potential temperature at ESP and the proxy of the WAG is an encouraging result if we take into account the completely different and fully independent nature of both series. Therefore, we conclude that the presence of a robust WAG helps ventilate the Western Mediterranean Deep Water and that the evacuation of this water is preferably achieved during the periods of stable and welldeveloped gyres, which usually coincide with the summerearly autumn season. On the contrary, wintertime, the season of weaker or even absent WAGs, favours the evacuation of the Levantine Intermediate Water. Due to the weakness of the signal and to some observed discrepancies, more research is needed to corroborate this hypothesis, which should include numerical modelling. The very subtlety of the mechanisms and processes involved and the complexity of the strait hydrodynamics anticipate the use of models that likely are beyond the state of the art of the models presently in use.

Data availability. The complete data set used in this paper is available at the PANGAEA repository with doi:10.1594/PANGAEA.864967 (García-Lafuente et al., 2016). 


\section{Appendix A}

In reference to the inset of Fig. 4a, the dispersion of dots around the mean values (written inside brackets hereinafter, $<\cdot \cdot>$ ) of CSN or CSS waters reflects their variability, which eventually will include Mediterranean signals advected by the outflow. The standard deviation (SD) is a good metric of such dispersion. If the mean water properties at ESP, $<T_{\mathrm{ESP}}>$, and $<S_{\mathrm{ESP}}>$, are farther than $n$ times the SD (the choice $n=3$ is adequate) from the mean value of the closest Mediterranean water (either CSN or CSS), it is reasonable to conclude that any Mediterranean signal that could have been advected by the outflow will have faded out in the observations at ESP due to mixing. This would happen whenever the fraction of North Atlantic Central Water in the mixing exceeds a threshold value, which may differ if we deal with salinity or temperature.

During the field experiment analysed in this paper, the distance from $<T_{\mathrm{ESP}}>$ to $<T_{\mathrm{CSN}}>$ (the closest water to ESP for temperature; see inset in Fig. 4a) is $0.047^{\circ} \mathrm{C}$, whereas $3 \times \mathrm{SD}$ $\left(T_{\mathrm{CSN}}\right)=0.065^{\circ} \mathrm{C}$. According to our reasoning, temperature signals in the Mediterranean waters have a chance of being detected in the $T_{\mathrm{ESP}}$ series. In the case of salinity, the distance from $\left.<S_{\mathrm{ESP}}\right\rangle$ to $\left\langle S_{\mathrm{CSS}}\right\rangle$ (the closest water now) is 0.080 , whilst $3 \times \mathrm{SD}\left(S_{\mathrm{CSS}}\right)=0.016$, which hardly is onefifth of the required value. Salinity is far from fulfilling the condition, so that salinity signals in the Mediterranean waters will almost certainly disappear in $S_{\mathrm{ESP}}$ series. Temperature is the right series to investigate Mediterranean signals in ESP. Although the previous numerical values are for the particular period when the data set was acquired and might not be valid for other periods, the conclusion that Mediterranean signals are better preserved in temperature than in salinity at ESP still holds because of the much greater difference in salinity than in temperature between the North Atlantic Central Water and the Mediterranean waters.

The fraction of North Atlantic Central Water in the mixed water at ESP necessary to erode the weak signals that could be in the Mediterranean waters is estimated now. Figure A1 sketches the mixing between North Atlantic Central Water, whose specific properties change along the double-headed arrow, and the underlying Mediterranean waters of characteristics CSN and CSS. The dots in the different outlined lines indicate possible results of mixing with different intervening fractions $\alpha_{\mathrm{CSN}}, \alpha_{\mathrm{CSS}}$, and $\alpha_{\mathrm{NAC}}$. The particular case we focus on is represented by the large empty dot (labelled ESP), which lies on the mixing line of thick dots. Obviously, the position of this dot in the $T-S$ diagram depends on the fractions participating in the mixing as well as on the assumed values for CSN and CSS.

The normalization condition,

$\alpha_{\mathrm{CSN}}+\alpha_{\mathrm{CSS}}+\alpha_{\mathrm{NAC}}=1$,

must be fulfilled in addition to Eq. (1). Our interest is the North Atlantic Central Water fraction $\alpha_{\mathrm{NAC}}$. Assuming that

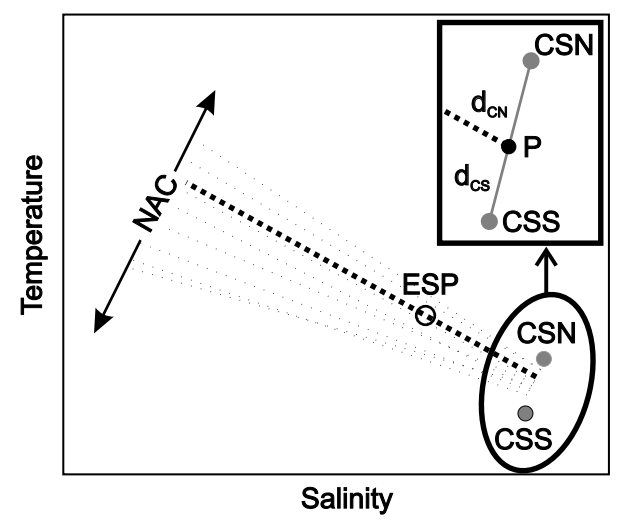

Figure A1. Sketch of the mixing between two Mediterranean waters of characteristics CSN and CSS (large filled dots) and the North Atlantic Central Water (NACW) (double-headed arrow) based on Fig. 4a (dimensions exaggerated). Several possible mixing lines with different fractions $\alpha_{\mathrm{CSN}}, \alpha_{\mathrm{CSS}}$, and $\alpha_{\mathrm{NAC}}$ have been sketched. The particular case of mixed water with characteristics ESP (empty dot), whose position in the $T-S$ diagram depends on the fractions intervening in the mixing, is discussed in the text. This empty dot can be seen as the result of a mixing between CSN and CSS to give point $P$ (see inset), followed by a subsequent mixing between $P$ and the NACW.

the mean properties of CSN and CSS $\left(<X_{\mathrm{CSN}}\right\rangle,\left\langle X_{\mathrm{CSS}}>\right.$, and $X$ representing $T$ or $S$ ) are known, Eqs. (1) and (A1) still contain five unknowns: the three fractions, $X_{\mathrm{ESP}}$, and $X_{\mathrm{NAC}}$. A new relationship between fractions $\alpha_{\mathrm{CSN}}$ and $\alpha_{\mathrm{CSS}}$ can be established if we see the final product $X_{\mathrm{ESP}}$ as the result of a first mixing between CSN and CSS to give point $P$, followed by a subsequent mixing between $P$ and the North Atlantic Central Water. The ratio of the fractions $\alpha_{\mathrm{CSN}} / \alpha_{\mathrm{CSS}}$ is inversely proportional to the ratio of the distances $d_{\mathrm{CN}}$ and $d_{\mathrm{CS}}$ (see inset of Fig. A1):

$\frac{\alpha_{\mathrm{CNS}}}{\alpha_{\mathrm{CSS}}}=\frac{d_{\mathrm{CS}}}{d_{C N}}=r$.

The ratio $r$ varies from 0 in which case point $P$ coincides with CSS (and $d_{\mathrm{CS}}=0$ ) to $\infty$ if $\alpha_{\mathrm{CSS}}=0$ (point $P$ moves to CSN and $d_{\mathrm{CN}}$ becomes 0 ). The interval $0.25<r<4$ $\left(\alpha_{\mathrm{CSS}}=4 \alpha_{\mathrm{CSN}}\right.$ to $\left.\alpha_{\mathrm{CSN}}=4 \alpha_{\mathrm{CSS}}\right)$ contains all the reasonable values of $r$ in practice.

Equations (1), (A1), and (A2) can be solved for the North Atlantic Central Water fraction $\alpha_{\text {NAC }}$ to give

$\alpha_{\mathrm{NAC}}=\frac{r\left(X_{\mathrm{ESP}}-<X_{\mathrm{CSN}}>\right)+\left(X_{\mathrm{ESP}}-<X_{\mathrm{CSS}}>\right)}{r\left(X_{\mathrm{NAC}}-<X_{\mathrm{CSN}}>\right)+\left(X_{\mathrm{NAC}}-<X_{\mathrm{CSS}}>\right)}$,

which contains three unknowns $\left(X_{\mathrm{ESP}}, X_{\mathrm{NAC}}, r\right)$ as long as $\left\langle X_{\mathrm{CSN}}\right\rangle$ and $\left\langle X_{\mathrm{CSS}}>\right.$ are known.

We will focus on the period of the field experiment and identify these means with the mean values displayed in the inset of Fig. 4a. Figure A2 shows contours of $\alpha_{\mathrm{NAC}}$ as a function of $X_{\mathrm{ESP}}$ and $X_{\mathrm{NAC}}$ for three different values of $r$ 

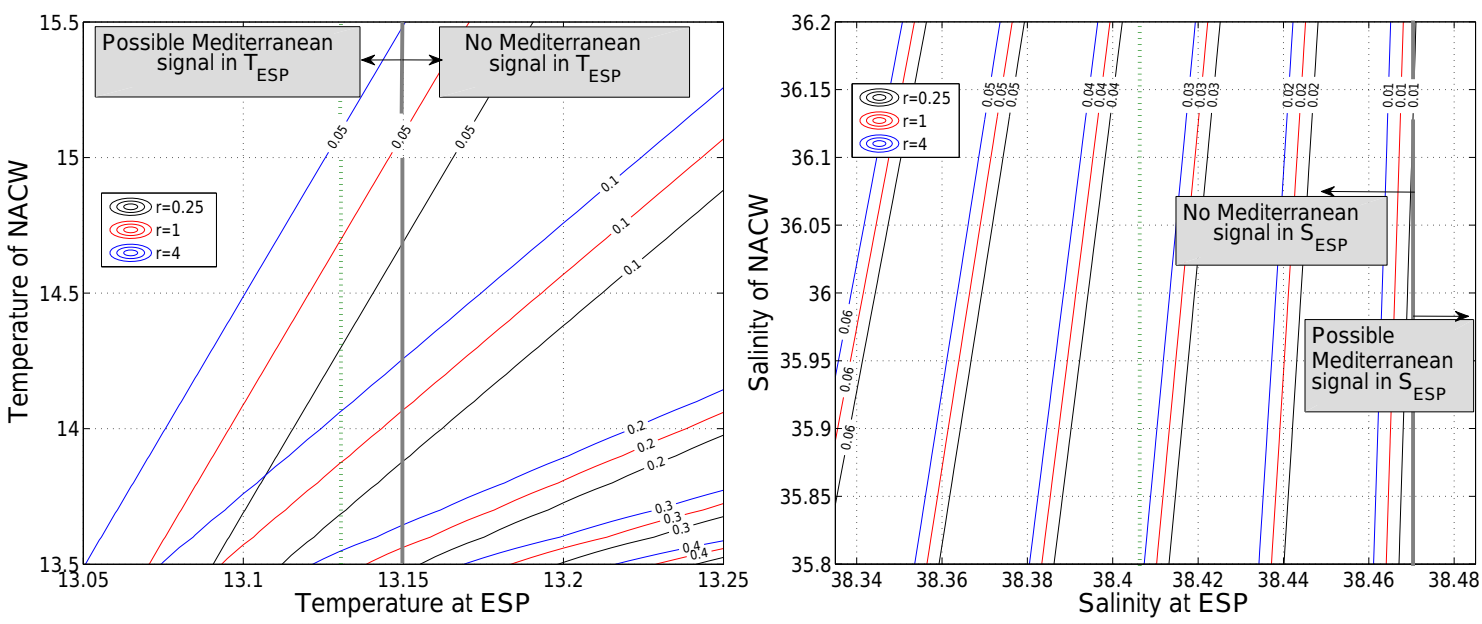

Figure A2. Left: contours of the fraction $\alpha_{\mathrm{NAC}}$ in the mixing (Eq. A3) as a function of North Atlantic Central Water (NACW) and final mixed water at ESP temperatures for three different values of the ratio $r$ (see legend; see also text for details). The green dashed line is the mean temperature at ESP in our data set, whereas the thick solid grey line represents the "threshold" value for keeping the chances of detecting, at least partially, the weak Mediterranean signals in the outflow at ESP. Right: same as left panel except for salinity.

and for both $X=T$ and $X=S$. While the fraction $\alpha_{\mathrm{NAC}}$ exhibits a small dependence on $r$ for low ratios in the temperature analysis (upper panel of Fig. A2), it is insensitive to $r$ in the salinity case. The mean values $<T_{\mathrm{ESP}}>$ and $<S_{\mathrm{ESP}}>$ observed at ESP during this period are plotted as dotted green lines, and the aforementioned threshold values as thick grey lines $\left(T^{*}=<T_{\mathrm{CSN}}>+3 \times \mathrm{SD}\left(T_{\mathrm{CSN}}\right)=13.15^{\circ} \mathrm{C}, S^{*}=\right.$ $\left.<S_{\mathrm{CSS}}>-3 \times \mathrm{SD}\left(S_{\mathrm{CSS}}\right)=38.47\right)$. The zones where signals in the Mediterranean waters could still be detected in the corresponding series at ESP for this particular period of time are indicated. Even when the criterion $3 \times \mathrm{SD}$ is arguable, the position of the observed $<S_{\mathrm{ESP}}>$ with regard to $S^{*}$ suggests that the probability of detecting Mediterranean signals in salinity at ESP is very low, whereas it is possible to find them in temperature.
Notice that both panels in Fig. A2 indicate a similar fraction $\alpha_{\mathrm{NAC}}$ of the order of 3.5 to $5.5 \%$ in the mixed water at ESP for typical values of North Atlantic Central Water $\left(T \sim 14.5^{\circ} \mathrm{C} ; S \sim 36.0\right)$, in agreement with previous estimates (García-Lafuente et al., 2007, 2011). This value is significantly greater than the $\sim 1 \%$ deduced from the lower panel of Fig. A2 in order to detect signals in

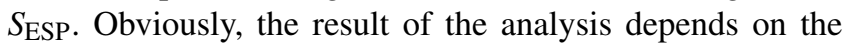
mean values of temperature and salinity at CSN and CSS $\left(<X_{\mathrm{CSN}}>\right.$ and $\left.<X_{\mathrm{CSS}}>\right)$, which change with time. For the expected fluctuations of these variables and the observed fractions of $\alpha_{\mathrm{NAC}}$, however, the possibility that the salinity observed at ESP provides useful information about the Mediterranean signals carried by the outflow is very unlikely. 
Competing interests. The authors declare that they have no conflict of interest.

Acknowledgements. Data from the monitoring station deployed at the Espartel Sill were collected in the frame of the Spanish Government-funded "INGRES" projects (REN2003-01608, CTM2006-02326, CTM2009-05810/MAR and CTM2010-21229C02-01/MAR). We are particularly grateful to the Spanish Institute of Oceanography (Instituto Español de Oceanografía), which allocated time of its terrific research vessels Ramón Margalef and Ángeles Alvariño to us for carrying out the field experiments and the maintenance of the monitoring station at the Espartel Sill. This station also contributes to the Mediterranean Sea monitoring network of the HYDROCHANGES program sponsored by the CIESM. The twin mooring lines deployed at the Camarinal Sill in the summer of 2013 are part of the experimental effort carried out within the Excellence Project MOCBASE (PE12-RNM-1540) funded by the Regional Government of Junta de Andalucía. C. Naranjo acknowledges a research contract associated with the Spanish funded project CTM2013-40886P. J. C. Sánchez-Garrido was supported by the Spanish Ministerio de Economía y Competitividad under the research contract JCI-2012-13451 of the "Juan de la Cierva" program. S. Sammartino acknowledges a post-doc contract of Junta de Andalucía linked to MOCBASE project. We also acknowledge the Copernicus Marine Environment Monitoring Service (CMEMS) for making the altimetry data used in this study freely available.

Edited by: M. Hoppema

Reviewed by: two anonymous referees

\section{References}

Bellanco, M. J. and Sánchez-Leal, R. F.: Spatial distribution and intra-annual variability of water masses on the Eastern Gulf of Cadiz seabed, Cont. Shelf Res., 128, 26-35, doi:10.1016/j.csr.2016.09.001, 2016.

Bryden, H. L. and Stommel, H. M.: Origin of the Mediterranean outflow, J. Mar. Res., 40, 55-71, 1982.

Bryden, H. L., Candela, J., and Kinder, T. H.: Exchange through the Strait of Gibraltar, Prog. Oceanogr. 33, 201-248, doi:10.1016/0079-6611(94)90028-0, 1994.

Candela, J., Winant, C., and Ruiz, A.: Tides in the Strait of Gibraltar, J. Geophys. Res., 95, 7313-7335, doi:10.1029/JC095iC05p07313, 1990.

Conan, P. and Millot, C.: Variability of the northern current off Marseilles, western Mediterranean Sea, from February to June 1992, Oceanol. Acta, 18, 193-205, 1995.

Flecha, S., Pérez, F. F., García-Lafuente, J., Sammartino, S., Ríos, A. F., and Huertas, I. E.: Trends of $\mathrm{pH}$ decrease in the Mediterranean Sea through high frequency observational data: indication of ocean acidification in the basin, Nat. Sci. Rep., 5, 16770, doi:10.1038/srep16770, 2015.

Fusco, G., Artale, V., Cotroneo, Y., and Sannino, G.: Thermohaline variability of Mediterranean Water in the Gulf of Cadiz, 1948-1999, Deep-Sea Res. Pt. I, 55, 1624-1638, doi:10.1016/j.dsr.2008.07.009, 2008.
García-Lafuente, J., Almazán, J. L., Fernández, F., Khribeche, A., and Hakimi, A.: Sea level in the Strait of Gibraltar: Tides, Int. Hydrogr. Rev., LXVII, 111-130, 1990.

García-Lafuente, J., Vargas, J. M., Plaza, F., Sarhan, T., Candela, J., and Bascheck, B.: Tide at the eastern section of the Strait of Gibraltar, J. Geophys. Res.-Oceans, 105, 14197-14213, doi:10.1029/2000JC900007, 2000.

García-Lafuente, J., Sánchez-Román, A., Díaz, G., Sannino, G., and Sánchez-Garrido, J. C.: Recent observations of seasonal variability of the Mediterranean outflow in the Strait of Gibraltar, J. Geophys. Res.-Oceans, 112, C10005, doi:10.1029/2006JC003992, 2007.

García-Lafuente, J., Delgado, J., Sánchez-Román, A., Soto, J., Carracedo, L., and Díaz, G.: Interannual variability of the Mediterranean outflow observed in Espartel Sill, Western Strait of Gibraltar, J. Geophys. Res.-Oceans, 114, C10018, doi:10.1029/2009JC005496, 2009.

García-Lafuente, J., Sánchez-Román, A., Naranjo, C., and SánchezGarrido, J. C.: The very first transformation of the Mediterranean outflow in the Strait of Gibraltar, J. Geophys. Res.-Oceans, 116, C07010, doi:10.1029/2011JC006967, 2011.

García-Lafuente, J., Naranjo, C., Sánchez-Leal, R., Sammartino, S., Bellanco, M. J., Sánchez-Garrido, J. C., and Soto-Navarro, J.: On the origin of the seasonal and interannual T-S variability of the inflow through the Strait of Gibraltar, Deep-Sea Res. Pt. I, 101, 38-53, doi:10.1016/j.dsr.2015.03.005, 2015.

García-Lafuente, J., Sánchez Garrido, J. C., Naranjo, C., and Sammartino, S.: ADCP current profiles and conductivity and temperature collected at two points of Camarinal Sill, Strait of Gibraltar, PANGAEA, doi:10.1594/PANGAEA.864967, 2016.

Kinder, T. H. and Bryden, H. L.: Aspiration of Deep Waters through Straits, in: The Physical Oceanography of Sea Straits, edited by: Pratt, L. J., NATO ASI Series, Springer Netherlands, 295-319, 1990.

Lique, C., Johnson, H. L., and Davis, P. E. D.: On the Interplay between the Circulation in the Surface and the Intermediate Layers of the Arctic Ocean, J. Phys. Oceanogr., 45, 1393-1409, doi:10.1175/jpo-d-14-0183.1, 2015.

Millot, C.: Another description of the Mediterranean Sea outflow, Prog. Oceanogr., 82, 101-124, doi:10.1016/j.pocean.2009.04.016, 2009.

Millot, C., Candela, J., Fuda, J. L., and Tber, Y.: Large warming and salinification of the Mediterranean outflow due to changes in its composition, Deep-Sea Res. Pt. I, 53, 656-666, doi:10.1016/j.dsr.2005.12.017, 2006.

Monserrat, S., López-Jurado, J. L., and Marcos, M.: A mesoscale index to describe the regional circulation around the Balearic Islands, J. Mar. Syst., 71, 413-420, doi:10.1016/j.jmarsys.2006.11.012, 2008.

Naranjo, C., García-Lafuente, J., Sánchez-Garrido, J. C., SánchezRomán, A., and Delgado-Cabello, J.: The Western Alboran Gyre helps ventilate the Western Mediterranean Deep Water through Gibraltar, Deep-Sea Res. Pt. I, 63, 157-163, doi:10.1016/j.dsr.2011.10.003, 2012.

Naranjo, C., Garcia-Lafuente, J., Sannino, G., and SánchezGarrido, J. C.: How much do tides affect the circulation of the Mediterranean Sea? From local processes in the Strait of Gibraltar to basin-scale effects, Prog. Oceanogr., 127, 108-116, doi:10.1016/j.pocean.2014.06.005, 2014. 
Naranjo, C., Sammartino, S., García-Lafuente, J., Bellanco, M. J., and Taupier-Letage, I.: Mediterranean waters along and across the Strait of Gibraltar, characterization and zonal modification, Deep-Sea Res. Pt. I, 105, 41-52, doi:10.1016/j.dsr.2015.08.003, 2015.

Parrilla, G., Kinder, T. H., and Preller, R. H.: Deep and intermediate Mediterranean water in the western Alborán Sea, Deep-Sea Res. Pt. A, 33, 55-88, doi:10.1016/0198-0149(86)90108-1, 1986.

Pinot, J. M., López-Jurado, J. L., and Riera, M.: The CANALES experiment (1996-1998), Interannual, seasonal, and mesoscale variability of the circulation in the Balearic Channels, Prog. Oceanogr., 55, 335-370, doi:10.1016/S0079-6611(02)00139-8, 2002.

Rhein, M., Send, U., Klein, B., and Krahmann, G.: Interbasin deep waterexchange in the western Mediterranean, J. Geophys. Res.Oceans, 104, 23495-23508, doi:10.1029/1999jc900162, 1999.

Sammartino, S., García-Lafuente, J., Naranjo, C., SánchezGarrido, J. C., Sánchez-Leal, R., and Sánchez-Román, A.: Ten years of marine current measurements in Espartel sill, Strait of Gibraltar, J. Geophys. Res.-Oceans, 120, 6309-6328, doi:10.1002/2014JC010674, 2015.

Sánchez-Román, A., Sannino, G., García-Lafuente, J., Carillo, A., and Criado-Aldeanueva, F.: Transport estimates at the western section of the Strait of Gibraltar: A combined experimental and numerical modeling study, J. Geophys. Res.-Oceans, 114, C06002, doi:10.1029/2008JC005023, 2009.
Sánchez-Garrido, J. C., Sannino, G., Liberti, L., García-Lafuente, J., and Pratt, L.: Numerical modeling of three-dimensional stratified tidal flow over Camarinal Sill, Strait of Gibraltar, J. Geophys. Res.-Oceans, 116, C12026, doi:10.1029/2011JC007093, 2011.

Sánchez-Garrido, J. C., García-Lafuente, J., Álvarez-Fanjul, E., Sotillo, M. G., and de los Santos, F.: What does cause the collapse of the Western Alborán Gyre? Results of an operational model, Prog. Oceanogr., 116, 142-153, doi:10.1016/j.pocean.2013.07.002, 2013.

Vargas-Yáñez, M., Plaza, F., García-Lafuente, J., Sarhan, T., Vargas, J. M., and Vélez-Belchí, P.: About the seasonal variability of the Alborán Sea circulation, J. Mar. Syst., 35, 229-248, doi:10.1016/S0924-7963(02)00128-8, 2002.

Vargas-Yáñez, M., Zunino, P., Schroeder, K., López-Jurado, J. L., Plaza, F., Serra, M., Castro, C., García-Martínez, M. C., Moya, F., and Salat, J.: Extreme Western Intermediate Water formation in winter 2010, J. Mar. Syst., 105-108, 52-59, doi:10.1016/j.jmarsys.2012.05.010, 2012.

Viudez, A., Pinot, J. M., and Haney, R. L.: On the upper layer circulation in the Alborán Sea, J. Geophys. Res.-Oceans, 103, 21653 21666, doi:10.1029/98JC01082, 1998.

Wesson, J. C. and Gregg, M. C.: Mixing at Camarinal Sill in the Strait of Gibraltar, J. Geophys. Res.-Oceans, 99, 9847-9878, doi:10.1029/94JC00256, 1994. 